\title{
Influence of COVID 19 on Transfer of Organizational Culture between Headquarters and Subsidiary and Role of Communication on the Process
}

DOI 10.18267/pr.2021.krn.4816.19

\author{
Jan Sochor \\ ORCID iD: not available \\ socj02@vse.cz \\ Prague University of Economics and business, Faculty of International Relations, \\ Department of International Business \\ Prague, Czech Republic
}

\begin{abstract}
Many studies consider organizational culture one of the main factors responsible for company success. The aim of this article is to explore how the current pandemic of COVID 19 influences the transfer process of organizational culture between HQ and the subsidiaries and what is the role of communication in the whole process. Facing the pandemic, change in working conditions, relaying on on-line communication and shifts in global economy present a challenge not only for transfer of the organizational culture within a company but can also pose a risk to the building blocks of the organizational culture itself. To explore this topic further, relevant literature was reviewed with focus on the most recent COVID 19 related research, survey developed and distributed to selected high level managers responsible for multi-country clusters and main findings further refined by interviews. The paper identifies key area of focus for companies whose global set up relies on doing business via global presence in markets through national subsidiaries, validates its findings and proposes additional research steps.
\end{abstract}

Keywords: organizational culture, subsidiary \& headquarters, COVID 19 pandemic, communication, transfer

JEL Classification codes: M14

\section{INTRODUCTION}

Organizational culture and its effects on effectivity and success of a company has been in the center of research for many decades and has been linked to firm's sustainable competitive advantage (Easterby-Smith et al., 2008). Organizational culture can therefore be seen as a certain synergy of resources and its coordination throughout the company leading to a desired outcome, and also as an endless quest for the right formula which will keep the members of the organization motivated and will be a source of personal satisfaction to employees (Selznick, 1957). It is also true that the environment in which companies do business is constantly changing and presenting them with new elements- both internal and external- such as employees, processes, technology, etc., which can therefore also act as a potential source of change. Considering this, current Covid19 pandemic represents large social as well as economic shock and change to the whole society and can have significant effects on changing the organizational culture. While academic research on the number and scale of effects is only starting, research already suggests that the pandemic presents major challenge for managers (Kniffin et al.,2020). One of the key questions they have to deal with is how they can build (or maintain) an organizational culture when everyone is working at home (Howard-Greenwille, 
2020) as the way we interact, do business and most of all communicate has changed overnight. Communication is essential in emergencies such as this and as a result of the new situation connected to spread of COVID 19 the communication immediately changed to virtual form (Sulkowski, 2020) which presents one of the major factors influencing change of the culture in organization. The world has changed for many people working in the corporate offices, and for many of them their home became their permanent office for many months to come.

While prior to pandemic, video conferences were one of the parts of communication, effective to communicate with business partners over continents and time zones and in some cases substituting the business travel, they now became the daily bread and only possible way of communication with your office peers that you had lunch with just a week ago. The expectation of the managers were that business should go as much as possible as usual and that they should adopt a new mindset that would allow them to achieve the same results in an environment where they usually rest (Mustajab et. al, 2020). Some topics such as cybersecurity became even bigger focus (Ahmad, 2020) and questions about working from home and the correlation with productivity were also raised (Himawan et al., 2020) as the working from home was viewed as potential threat to productivity. When looking at overall picture, this pandemic is challenging the current status quo of many companies on different levels and the ability of the companies to adapt is a crucial factor in their sustainable success.

The aim of this article is to briefly define organizational culture and establish the importance of the recent pandemic as the dominating factor which can potentially change the organizational culture due to new working normal for many international companies while considering the most recently published research and findings and further to continue in this exploratory research via questionnaires and follow up interviews with selected high level managers responsible for multi-country clusters. The paper then identifies the key area of focus for companies whose global set up relies on doing business via global presence in key markets through national subsidiaries, validates the research findings on ongoing process of transfer of organizational culture and proposes additional research steps.

\section{LITERATURE REVIEW}

When looking at a most basic definition of organizational culture we can say that it is "the way things are done around here" (Deal \& Kennedy, 2000). According to Schein, there are three crucial dynamics regarding the culture: creation, evolution and managed change (Schein, 1985). All these three phases are very essential and understanding the processes behind them helps us to understand the overall organizational culture. To further support the point of organizational culture being fluid and ever changing, research has shown that the organizational culture is always evolving and that organizations should asses their culture regularly (Warrik, 2017) as its transformation is endless. While even during normal times, there is number of external and internal factors influencing and potentially changing the culture of the company, the recent pandemic has taken over the corporate world by storm and poses serious challenge to existing framework of each individual corporation and its culture. As argued by McGowan, the fundamental values have gained more attention during the recent pandemic, truly showing the strength of the culture of each company (McGowan, 2020). This new and unprecedented situation puts the world and global economy into unknown territory and has influenced people in all aspect of their work as well as social and family life and in return can have significant impact on organizational structure and its components. Using the model from Serrat, we can see the 10 components that he considers to be parts that shape organization culture (Serrat, 2017). And while none of them can shape the organizational structure, all of them are influencing it. 


\section{Fig. 1 Components of organizational culture}

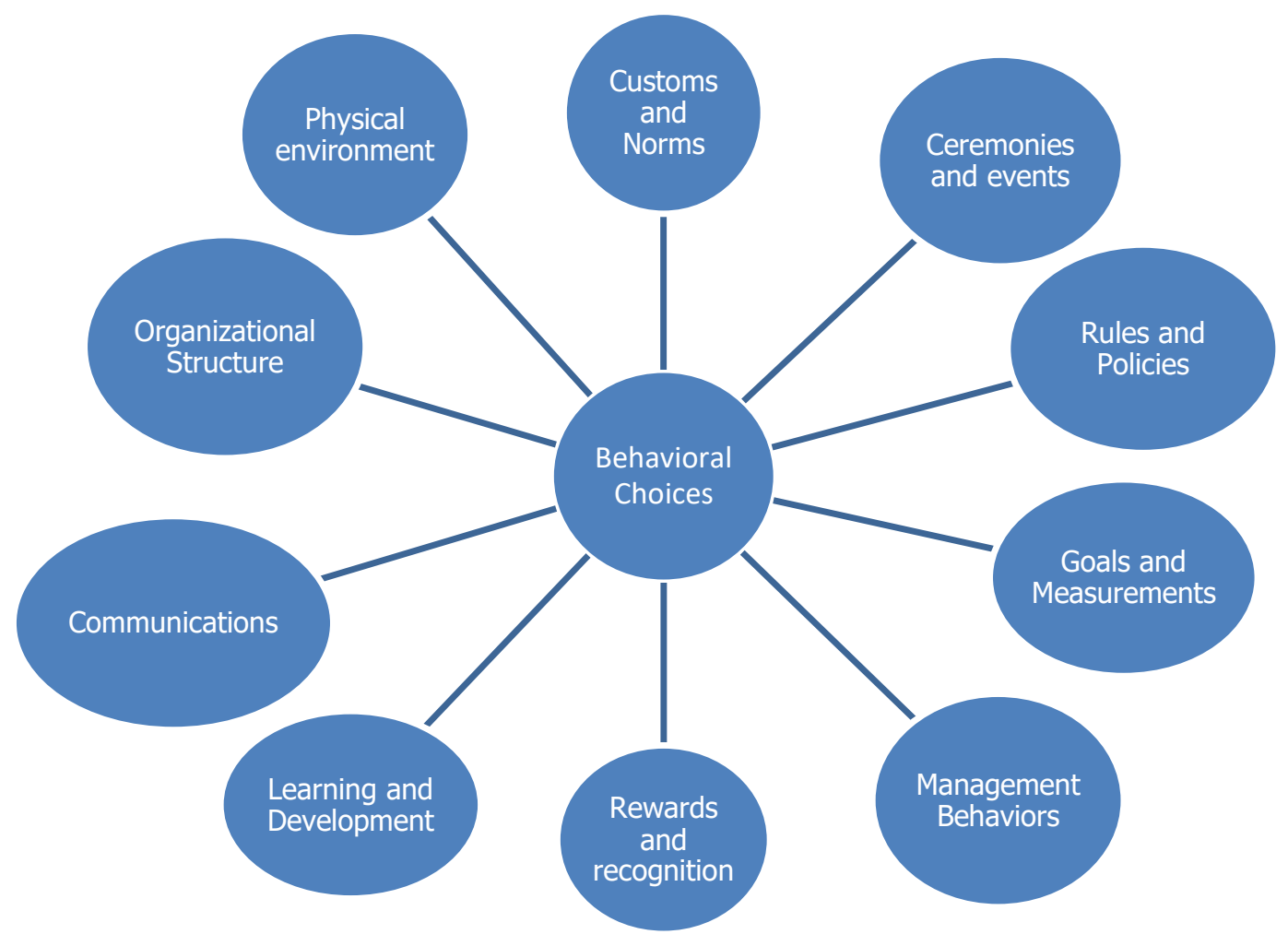

Source: Serrat, 2017

When looking at the figure above, we see that due to recent COVID19 situation, all of the above categories have the potential to be influenced by the pandemic. While some of the categories, compared to others, may go through less dramatic immediate change (Goals and Measurements, formal Organizational Structure, Learning and Development, Rules and Policies, Customs and Norms), they are still influenced in some ways as new rules have to be made for work from home and all learning has to take form via e-learning. Formal organizational structure can also, albeit later, be adjusted to better fit the challenges of the dynamically changing environment. New customs and norms may be formed as those which were tied to workplace can no longer be observed. Other categories from Figure 1 are heavily influenced by this and with immediate effect. Physical environment has changed immediately as new norm for majority of white-collar workers became working from home. This is true also for all of the related activities in which the employee is very much engaged with the companysuch as Ceremonies and Events, Management Behaviors and Communication- and these will be discussed in more detail in one of the following sections. which would have to change due to lack of physical contact with coworkers. Economic situation of each company as well as government ordered restrictions and lockdowns could also have immediate impact on Rewards and recognition. Taken all of this above, organizational culture is facing significantly changing environment from many angles resulting from a dramatic change due to pandemic.

Significant research exists on how such dramatic change in the environment can affect the organization and its actions. The range of actions can be very wide. It can lead to overreacting as confirmed by Hallett who witnessed that when a school principal was faced with budgetary cuts, his rigid push for new rules of accountability finally led to alienating the teachers which in turn undermined their performance(Hallett, 2010). In other case, these changes can even radicalize the culture as it happens when the norms, common practices and assumptions are discarded and people give to experiment with more radical alternatives as could be seen during Occupy Wall Street protests during which people arose against established corporate 
cultures and started to experiment with other alternatives very often more radical (Reinecke, 2018). One of the examples which combines both over-reaction on a company part and radicalization on the employee part can be a reaction to salary pay cuts or non-payment of bonuses which some of the companies introduced shortly after the pandemic started.

As already established above, one of the important aspects of conducting business is communication. Proper communication is not only of the most importance during emergencies, but it may also change its form given the current conditions. This aspect has changed due to pandemic almost overnight leading to massive virtualization of communication (Sulkowski, 2020) which in itself is one of the factors that can have significant impact on culture. Many studies have linked what a pivotal role communication plays in the business world. For example, Morley et. Al. (2002) presented how," Organizations that develop effective communication processes are more likely to both have positive work environments and be more effective in achieving their objectives." Following this example, we can derive that effective communication may contribute to better job satisfaction for employees and in turn allow the corporation to achieve better economical KPIs. Further, in their research, ZwijzeKonning and de Jong concluded in their research that, "The importance of communication for the effectiveness of organizations and the well being and motivation of employees is undisputed" (Zwijze-Konning \& de Jong, 2005).

Based on the above, we have established that while communication is an integral role of organizational structure and plays important role in building it, it also represents potential threat to transfer of organizational culture as it became virtual overnight. In times when companies face significant changes to the environment, they undertake different actions to keep their employees engaged in order to overcome certain issues, for example virtualization of communication. Based on the available research (Jena et. al, 2018) engaged personnel is always optimistic and shows high level of performance in the organization. Results from other research (Tiwari and Lenka, 2019) also shows among others, internal corporate communication as well as knowledge sharing were positively associated with employee engagement. From the above, we can see that how company communicates during dramatic environmental changes can have significant effect on most of the components of organizational culture as seen in Figure 1 and also on engagement of the employees which is critical especial during this time. This identified topic was subject to further study via the survey as well as follow up interviews.

\section{METHODOLOGY}

In order to get more insight on this topic, two-step methodology methods of investigation were developed for the aim of the work. In a first step, seven-question survey was developed to identify how the selected companies dealt with communication towards subsidiaries during the pandemic and how (and if) they approached the subsidiaries regarding the development of organizational culture. The selected group of respondents was also asked to identify what tools and drivers they consider to be most effective for proper transfer of organizational culture.

We shared the survey with selected group of 10 international managers who are either responsible for regions or manage multi-country clusters. Due to time limitations, 6 of the 10 were then selected and 20 minute follow up call was conducted to explore the topics further. While follow up interview can have somewhat limited research significance, it was established that it can provide additional added value to investigations as it offers broad overviews of title and its impact (Sukamolson, 2007). We believe that the follow up interview had additional value as it was an extension and elaboration from already evaluated survey and thus allowed to probe and gain insight on specific questions and topics raised in the questionnaires and 
further explore topics where the responses were very similar. Due to the limitations of time allotted for the conversation, we have decided for semi-structured interview, which can be referred to as "discovery interview" and which allows a "guided conversation" as it is more flexible when compared with structured interviews which are more similar to formal or job interviews (Saul, 2014).

The group of selected managers represented five corporations from consumer goods industry, two from retail sector and one each from software company, international law firm and CEE marketing agency.

\section{RESULTS AND DISCUSSION}

\subsection{Research finding from the survey}

The results obtained from the literature review showed that engagement and communication during dramatic change in environment are key components of keeping the organizational culture strong and potentially changing it if the need arises.

The results from the survey pointed to several common denominators which included the following observations:

- 8 out of 10 managers strongly believed that the virtualization of communication led to meetings being conducted in more formal matter and adhering to stricter rules. 3 of the managers specifically mentioned that the meetings were more rigid and less innovative. 6 of the managers stated that they the quality and level of communication among their staff has deteriorated

- Only 2 out of 10 managers stated that they knowingly engaged in building the organizational structure during the pandemic.

- 9 out of 10 managers felt that overall employee engagement is lower when working from home

Tab. 1 Key drivers for proper transfer of organizational culture to subsidiaries

\begin{tabular}{|l|l|}
\hline CEO & 8 \\
\hline Subsidiary's GM and HR Department & 7 \\
\hline International Meetings and Events & 6 \\
\hline Company Global Trainings and Developments & 3 \\
\hline HR Onboarding Materials/Videos & 2 \\
\hline Local Team Buildings & 2 \\
\hline PR Releases and HR Info Sent Regularly To Employees & 1 \\
\hline Others & 1 \\
\hline
\end{tabular}

Source: author

Managers were also asked to pick their top three choices regarding the key drivers for proper transfer of organizational culture to subsidiaries. From the below table a clear picture of the preferences can be derived. While 8 out of 10 chose CEO as one of the key drivers, 7 of them opted for the GM and HR department of the subsidiary and 6 of them chose international meetings and events as vehicles for transfer. 
In general, the results from the managerial survey were consistent in two major areas. First, communication became more formal and more effort was needed by the managers (but also their staff) to keep up previous level of communication. Secondly, employee engagement was much lower when the pandemic started. Strong employee engagement and its positive effect on organizational structure has been already established by many researchers who showed strong correlation between these two variables (Kalianan, Adjovu, 2015). As employee engagement, part of which is communication throughout the company, is one of the major prerequisites for building an organizational culture, the follow up interviews focused on exploring further the views of the managers about the way how the organizational transfer process changed in their opinion, referencing the key drivers from Table 1 and can continue given the current limitations during pandemic times.

\subsection{Research findings from the follow up interviews}

Most of the managers (60\%) chose the combination of CEO role, GM and HR department of the subsidiary and International meeting and events as key drivers for transfer of organizational culture to subsidiaries. While some of them also considered other drivers to play a role in this process, they felt these remaining drivers from Table 1 were more of a regular part of the process (Trainings and Developments, Onboarding materials), were not particularly related to global organizational culture (Local team buildings) or simply were not as related to organizational culture overall (PR releases and HR info). Therefore, part of the interview was dedicated to the top three categories from Table 1.

CEO- vast majority of managers (80\%) agreed that the role of CEO is pivotal as he/she has to act as a leader and is the main "vessel" according to one of the managers, of how to change or keep organizational culture within the company. Several managers stated that the CEO's value and importance rise in times of crises such as this pandemic. They also described that the actions of their CEO have partially changed during the pandemic as many of them started to communicate via video calls in regular timeline (weekly or bi-weekly) to update the employees of the company on the overall picture and to boost their spirits. They also ensured their increased engagement by this action.

Subsidiary's GM and HR Management- majority of managers (70\%) also considered the local leadership to be extremely important during pandemic. One of the regional managers from consumer industry corporation stated: "We have invested a lot into our country and cluster management and always focused on having a strong leaders in a GM positions. When else but now during pandemic, we should let them fully manage the market which they know the best". This was also a view of most of the other managers that came up during the interviews. As the situation varied country by country, regional managers were often in position of not knowing the exact situation in each country and had to depend and trust the local management to get through the pandemic. Few of them also mentioned that they shared with the local management a flexible game plan which highlighted major DO's and DON'T's and let the locals adjust it to the specific country conditions. Thus they ensured their engagement and let them apply it to the country teams further, albeit unknowingly, making sure that the process of transfer of organizational culture does not stop.

International meeting and Events- $60 \%$ of managers described this as a key driver as they believe that the setting of the meetings and events and the overall atmosphere can enhance the transfer of organizational culture and allow the participants to "soak it in". All of them also agreed that their companies are not planning any global or regional in person meetings in foreseeable future and that this has influenced their work as well. Four of the managers stated that their companies started to do global meetings online and also tried to introduce a fan factor as a part of it- for example live online appearance of brand ambassadors, artists or other 
well know people. During interviews, majority of them also agreed that currently, they do not feel that lack of the meetings is representing any major risk for their organizational culture, however, that their companies started to look at ways how to conduct these meetings in the future.

\subsection{Pressure Cooker}

From our discussion with the managers, it became also clear that they felt extreme pressure both on themselves but also on their staff to get through this period successfully. $60 \%$ of the managers also admitted that they had higher than usual expectations of the staff during this period and all of them admitted to higher pressure from CEOs and management board. When we take a step back and look at the overall environment conditions and take into consideration significant changes in the working environment (working from home), additional pressure from the organizations to keep the productivity and significant impact from the pandemic on personal life of the employees (social and economical changes, home schooling of kids, health topics, etc.), we clearly see that many of the employees were subject to extreme pressure in their daily live. The word "pressure" resonated throughout the interviews and could be visually summed up as below.

\section{Fig. 2 Pressure Cooker}

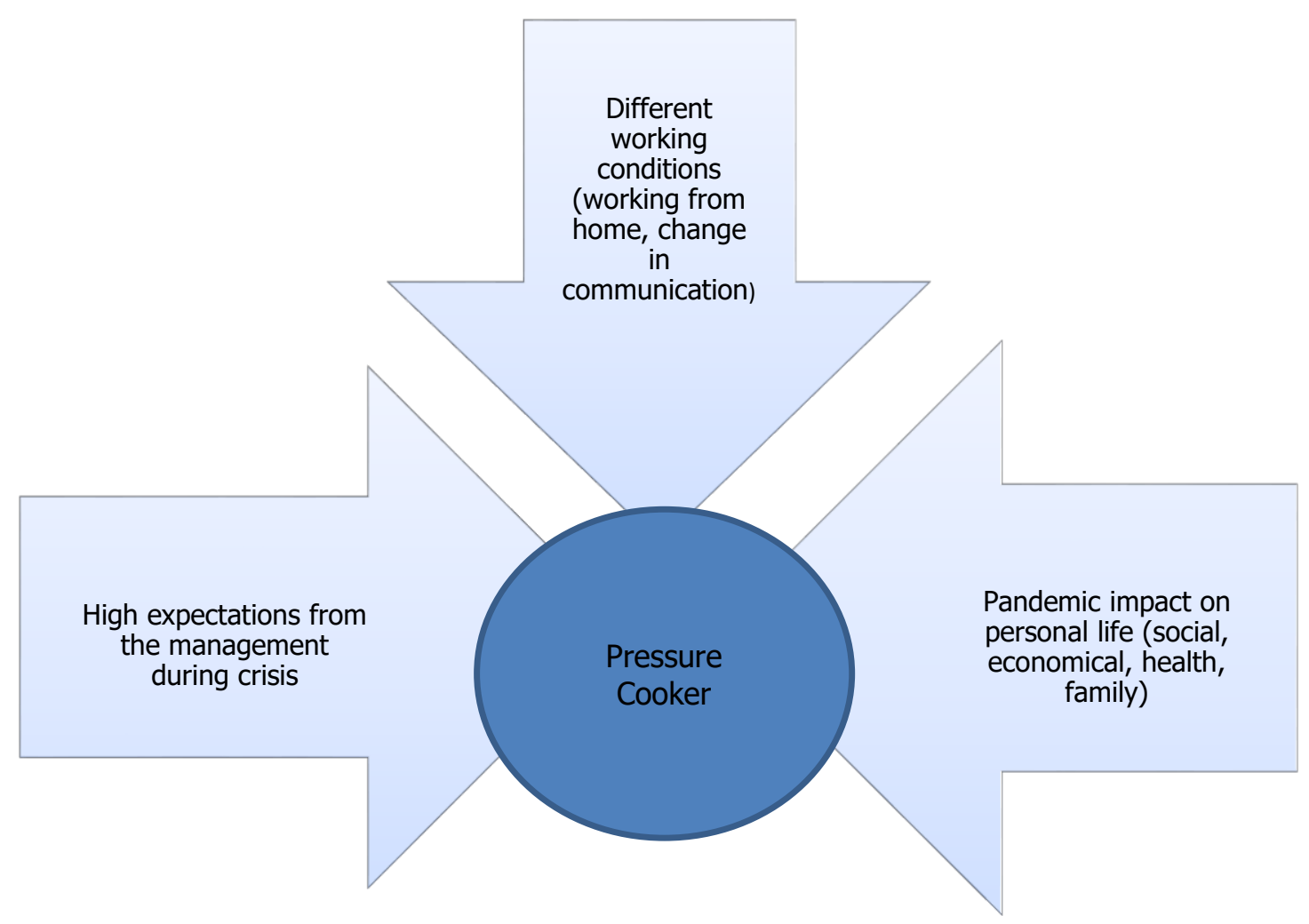

Source: author

When taken into consideration the great amount of pressure that resulted rom the pandemic, it is clear that this can be a major factor going forward and could potentially have impact not only on organizational culture but overall well-being of the employees and performance of given corporation. While the scope of this paper does not allow for furthermore detailed research, it is certainly worth noting that the managers have identified this phenomenon, which could be a topic for additional research. 


\subsection{Keeping people engaged and allowing for proper transfer}

From our discussion with the managers, there was one clear underlying theme. Although they did not fully realize it, the actions of their CEO as well as theirs towards the country management team ensured that the process that would allow for transfer of organizational culture would continue. When discussing their specific actions during the interviews and comparing them with facts from already existing studies and the key drivers identified in Table 1 , clear actions related to engagement of the employees and transfer of organizational culture can be seen. Below are some of the findings resulting from the interviews.

Several studies exist on the topic of how to manage during turbulent times while keeping employees focused and engaged. Robinson, for example, suggests making sure that employees have proper tools to do their job (Robison, 2009). This was also discussed with the managers and $50 \%$ of them mentioned that the company bought additional equipment for the people who were working from home. $40 \%$ of the managers stated that the company allowed the people to take certain equipment (monitors, keyboards, computers) home for the duration of their work there. In another studies, Robertson summarizes that in order to enhance employee engagement in difficult times, organizations need to make the employees feel that they are truly interested in them (Robertson, 2012) and Groove Management Blog states (Formato, 2014) that leaderships needs to be more visible in tough time than at any other time. These observations correlate strongly also with findings from our research as the managers mentioned that for example their CEOs started to do regular weekly videos where they informed the employees of the current situation and thus increased their engagement. Four of the managers also mentioned that their companies did not cut any benefits during the pandemic and actually tried to find different ways how to offer benefits which would be available during the pandemic. One of the examples was that the company decided to give their employees lunches and deliver them to their doorsteps for one day per week and have lunch together via video conference. This finding is supported by another research (Deal, Stawiski, and Gentry, 2010) which shows that during turbulent times, additionally received benefit packages keep the employees engaged and motivated. That much more as some of the benefits (gym membership, company car, tickets for cultural events) were not applicable due to pandemic. From the above findings, we conclude that the findings from our research are confirmed and validated by previous research focused on actions during dramatic environmental change.

\section{CONCLUSION}

While there are certain limitations to this study, especially the limited scope of the research as well as the use of short survey and interview method, we argue that COVID 19 pandemic did not stop the transfer of organizational culture although in many cases this process continued mainly unknowingly while driven by CEOs as well as regional and country management who took number of actions during pandemic as described above. It is also important to realize that the workforce was subject to severe changes in their work as well as personal life as shown in the Pressure Cooker model and that managers need to be aware of this before taking appropriate actions to remedy the situation to the fullest. This phenomenon could be also subject of further research as it will impact the future behavior of employees. While the pandemic is not over yet as of February 2021, it is clear that many corporations were able to deal with challenges such as working from home, change in communication and lack of certain interaction events to keep their members engaged and focused even though they were/are going through rapid change in the business environment. The effects of COVID 19 pandemic are getting much attention from the researchers and one area of possible further research is to study how, in the future, corporations will deal on a global scale with international meetings, 
conventions, events and personal interactions which was one of the most important areas for transfer of organizational culture identified during our research.

\section{REFERENCES}

Ahmad, T. (2020) Corona Virus (COVID-19) Pandemic and Work from Home: Challenges of Cybercrimes and Cybersecurity. Digital Learning. Retrieved February 10 2021, from https://ssrn.com/abstract=3568830.

Deal T. E. and Kennedy, A. A. (2000) Corporate Cultures: The Rites and Rituals of Corporate Life, Harmondsworth, reissue Perseus Books.

Deal, J. J., Stawiski, S., \& Gentry, W. A. (2010). Employee engagement. Has it Been a Bull Market? QuickView Leadership Series. A Center for Creative Leadership Report Sponsored by Booz Allen Hamilton. Retrieved January 18, 2021, from: http://www.ccl.org/leadership/pdf/research/EmployeeEngagement.pdf

Easterby-Smith, M., Lyles, M. A., \& Tsang, E. W. (2008). Inter- organizational knowledge transfer: Current themes and future prospects. Journal of management studies, 45(4), 677690. https://doi.org/10.1111/j.1467-6486.2008.00773.x

Formato, B. (2014). Why employee engagement is so critical during tough times. Groove Management Blog. Retrieved February 10, 2021, from https://www.groovemanagement.com/blog/why-employee-engagement-is-so-critical-duringtough-times

Himawan, K., Fanggidae, J.P., \& Helmi, J. (2020). The Sociocultural Barriers of Work-FromHome Arrangement Due to COVID-19 Pandemic in Asia: Implications and Future Implementation. Preprint. https://doi.org/10.31124/advance.12250190.v1

Hallett, T. (2010). The myth incarnate: Recoupling processes, turmoil, and inhabited institutions in an urban elementary school. American Sociological Review, 75, 52-74. https://doi.org/10.1177/0003122409357044

Howard-Grenville, J. (2020). How to sustain your organization's culture when everyone is remote. MIT Sloan Management Review, June, 1-4.

Jena, L. K., Pradhan, S., \& Panigrahy, N.P. (2018). Pursuit of organisational trust: Role of employee engagement, psychological well-being and transformational leadership. Asia Pacific Management Review 23(3): 227-234. https://doi.org/10.1016/j.apmrv.2017.11.001

Kaliannan, M., \& Adjovu, S. N. (2015). Effective Employee Engagement and Organizational Success: A Case Study. Procedia - Social and Behavioral Sciences: 172, 161-168. https://doi.org/10.1016/j.sbspro.2015.01.350

Kniffin, K., Narayanan, J., Anseel, F., Antonakis, J., Ashford, S. P., Bakker, A. B., Bamberger, P., Bapuji, H., Bhave, D. P., Choi, V. K., Creary, S. J., Demerouti, E., Flynn, F. J., Gelfand, M. J., Greer, L. L., Johns, G., Kesebir, S., Klein, P. G., Lee, S. Y., Ozcelik, H., Petriglieri, J. L., Rothbard, N. P., Rudolph, C. W., Shaw, J. D., Sirola, N., Wanberg, C. R., Whillans, A., Wilmot, M. P., \& Vugt, M. V. (2020) Covid-19 and the workplace: Implications, issues and insights for future research. American Psychologist. Forthcoming.

McGowan, H.E. (2020). How the Coronavirus Pandemic Is Accelerating the Future of Work USENET. Retrieved January 24th, 2021, from https://www.forbes.com/sites/heathermcgowan/2020/03/23/the-coronavirus-pandemicaccelerates-the-future-of-work-and-provides-opportunity/\#7ccdfd42317f 
Morley, D., Shockley-Zalabak, P., \& Cesaria, R. (2002) Organizational influence processes: perceptions of values, communication and effectiveness, Studies in Communication Sciences, 2, 69-104. https://doi.org/10.5169/seals-790899

Mustajab, D., Bauw, A., Rasyid, A., Irawan, A., Akbar, M. A., \& Hamid, M. A. (2020). Working from Home Phenomenon as an Effort to Prevent COVID-19 Attacks and Its Impacts on Work Productivity. The International Journal of Applied Business TIJAB, 4(1). http://dx.doi.org/10.20473/tijab.V4.I1.2020.13-21

Reinecke, J. (2018). Social movements and prefigurative organizing: Confronting entrenched inequalities in occupy London. Organization Studies, 39, 1299-321. https://doi.org/10.1177/0170840618759815

Selznick, P. 1957. Leadership in administration: A sociological interpretation. New York: Harper \& Row.

Robertson, I. (2012). The importance of employee engagement in difficult times. The Guardian. Retrieved January 17, 2021 from: https://www.theguardian.com/public-leadersnetwork/2012/may/03/importance-employee-engagement-difficult-times

Robison, J. (2009). Building engagement in this economic crisis. Gallup Business Journal. Retrieved January 6,2021 from https://news.gallup.com/businessjournal/115213/buildingengagement-economic-crisis.aspx

Saul, M. (2014) Simply Psychology. Retrieved January 20th, 2021, from https://www.simplypsychology.org/interviews.html

Schein, Edgar H. (1985): Organizational Culture and Leadership. San Francisco: Jossey-Bass Publishers

Serrat O. (2017) A Primer on Organizational Culture. In: Knowledge Solutions. Springer, Singapore. https://doi.org/10.1007/978-981-10-0983-9_40

Selznick, P. (1957). Leadership in administration: A sociological interpretation. New York: Harper \& Row.

Sukamolson, S. (2007). Fundamentals of quantitative research. Retrieved January 15, 2021 from http://www.culi.chula.ac.th/eJournal/bod/Suphat\%20Sukamolson.pdf

Sulkowski, L. (2020). "Covid-19 Pandemic; Recession, Virtual Revolution Leading to Deglobalization?" Journal of Intercultural Management, 12 (1), 1-11. Retrieved February 10, 2021 from https://content.sciendo.com/view/journals/joim/12/1/article-p1.xml?language=en

Tiwari, B., \& Lenka, U. (2019). Employee engagement: A study of survivors in Indian IT/ITES sector. IIMB Management Review, 32(3). https://doi.org/10.1016/j.iimb.2019.10.003

Warrik, D.D. (2017), What leaders need to know about organizational culture. Business Horizons. 60. pp. 395-404. https://doi.org/10.1016/j.bushor.2017.01.011

Zwijze-Koning, K.H., \& de Jong, M.D.T. (2005). Auditing information structures in organizations: A review of data collection techniques for network analysis, Organizational Research Methods, 8, 429-453. https://doi.org/10.1177/1094428105280120 